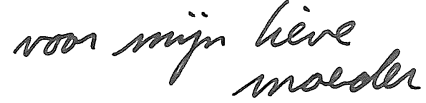

\title{
THE YAKKHA VERB: INTERPRETATION AND ANALYSIS OF THE OMRUWA MATERIAL (A KIRANTI LANGUAGE OF EASTERN NEPAL)
}

\author{
By George VAN DrIEM \\ Rijksuniversiteit Leiden
}

In 1989 Jadranka Gvozdanović published data of the 'Yakkhaba' transitive verbal paradigm. In the present paper these data are identified as Yakkha, re-arranged and interpreted. Comparisons are made with other Kiranti verbal agreement systems and with my model of the Proto-Kiranti verb.

\section{Yakkhaba, Yakkha and Yakthungba}

Kiranti languages are native to eastern Nepal and the western fringe of Sikkim. The Kiranti branch of the Tibeto-Burman is characterized by verbal morphologies which by Tibeto-Burman standards may be called complex. The Kiranti languages are traditionally divided into Limbu, Yakkha and the Rai languages. Limbu, at the far eastern extent of the Kiranti homeland, has several dialects, of which Pãcthare ${ }^{1}$ (Weidert and Subba, 1985) and Phedāppe (van Driem, 1987) are the best described. Yakkha occupies an intermediate position and is spoken in the vicinity of Cainpur in Sañkhuvā Sabhā district on the slopes east of the Arūn river. Rai (Nep. Rā̃) is a highly heterogeneous group of languages. This has to do with the fact that the name Rai, although convenient, is not a proper linguistic designation, but represents what in Nepal is perceived to be an ethnic grouping.

Yakkhaba is a 'Rai' language of Sañkhuvā Sabhā district. Historical phonology, however, suggests that Yakkhaba belongs to the same subgroup within Kiranti as Yakkha and Limbu (autonym Yakthumba). This subgrouping has been dubbed 'Eastern Kiranti' and comprises all Kiranti languages east of the Sālpā watershed (van Driem, 1990b). The Yakkhaba are divided into three tribes which represent at least two distinct dialects: Lohorung just north of the district centre of Khādbārī, and Yamphe and Yamphu further north in the area surrounding the confluence of the Kāsuvā and the Arūn.

I have published a morphological analysis of the Lohorung verb and am presently writing a grammar of the Lohorung language (van Driem, 1992 and forthcoming $b)^{2}{ }^{2}$ Rutgers, who is currently writing a grammar of the closely related Yamphu language, spoken in Hedānnā village and surrounding hamlets, has prepared an analysed native text with grammatical commentary and a morphological analysis of the Yamphu simplex conjugation (Rutgers, 1992a, 1992b). The names Lohorung [lohoruy], Yamphu and Yamphe are tribal designations. All three groups call their language [yakkhaba khap] 'yakkhaba language'.

\footnotetext{
${ }^{1}$ Written Nepali in the devanāgari script is transliterated in accordance with indological tradition with two additional conventions adopted specifically for Nepali. Mute $a$ is not transliterated, even when it has not been deleted by a virām in the native orthography. Whereas a bindu or an orthographic half-nasal are transliterated as the corresponding nasal consonant, a candrabindu is transliterated as a tilde above the vowel.

${ }^{2}$ The author is grateful to his student Roland Rutgers for pointing out that the label 'nonsingular patient morpheme' (nsP) for the Lohorung morpheme $<-c i\rangle$ in sf6 is inaccurate in view of the distribution of the morpheme in $3 \rightarrow 3$ forms (van Driem, 1992). The label for this morpheme should therefore be 'non-singular number of a third person actant' (ns3), which meaning this suffix indexes in all indicative forms where non-singular number of a third person actant is not indicated by another morpheme, viz. the dual suffix $<-c i>$ or third person plural suffix $<-m i>$, both in sf 3 of the Lohorung simplex.
} 
Gvozdanović collected her 'Yakkhaba' data in 1984. They 'originate from Lal Bahadur Rai, male aged 51, from village Omruwa, ward 3, in panchayat Ankhibhuin, district Sankhuwasabha in East Nepal, who had spent 25 years at his birthplace, 24 years afterwards in Nagaland in India, and is now living in Dharan, district Sunsari.' 'Ākhībhuĩ' (like Lāmīdãdāă, Pākhribās, Dobhāne and many more) is a popular Nepalese toponym, yet the Âkkhībhuĩ in Sañkhuvā

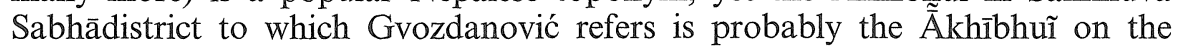
eastern slopes overlooking the Arūn river about $20 \mathrm{~km}$ south of Khādbārī and $20 \mathrm{~km}$ north of Hile, between the Leguvā and Piluvā, two eastern tributaries of the Arūn. This $\tilde{\mathrm{A}} k$ hībhuĩ and, in fact, all the Kiranti area surrounding Cainpur is Yakkha territory. The fact that Lāl Bahādur Rāī apparently called his language 'Yakkhaba' suggests that the Yakkha too, or some Yakkha, refer to themselves or to their language as yakkhaba. This is not much of a surprise because the suffix $-b a$ is a widespread masculine nominalizing suffix in Eastern Kiranti. For example, the Limbu autonym is yakthun, but also yakthunba.

These geographical data alone already suggest that the language which Gvozdanović studied is Yakkha. The language data themselves, however, unequivocally establish that the language is Yakkha and not Yakkhaba (Lohorung, Yamphe, Yamphu). The verb 'mokma' which Gvozdanovic gives for 'to beat' has previously been recorded as the Yakkha verb for 'to beat, to strike': Hodgson (1826: 346-7) records Yakkha 'mók'tu' for 'strike[s]', and Grierson (1909: 308) also list the same Yakkha verb, e.g. 'moktugā' for '[thou] beatest'. By contrast, the stems of the corresponding Limbu and Lohorung (Yakkhaba) verbs are <hipt $\sim$ hip $>$ and <rogu $\sim$ rok> respectively. Gvozdanović records the pronouns: $k a$ ' $I$ ', kenci 'we (dual inclusive)', kanci 'we (dual exclusive)', kening 'we (plural inclusive)', kaning 'we (plural exclusive)', nda 'you (singular)', ningda 'you (dual and plural)', ung 'he, she', ungaci 'they (dual and plural)'. This does not correspond completely with the less exhaustive list of Yakkha pronouns given by Grierson (1909: 307): $k \bar{a}$ ' $\mathbb{I}$ ', $k \bar{a}-n g \bar{a}$ 'by me', $\bar{a}$ ning, $k \bar{a}-n i$ 'we', ing-khi 'thou', ing-khi(-ni), in-ning-khik 'you', $i-k h i, u-k h i$ 'he', u-jing-khi, ikha-zi 'they'.

It has become common practice to call Kiranti peoples by their Nepali names, i.e. as they are referred to by the Indo-Aryan Nepalese, e.g., Lohorung (tribal autonym lohoruy, language autonym yakkhaba khap), Yamphu (tribal autonym yamphu, language autonym yakkhaba khap), Yamphe (tribal autonym yamphe, language autonym yakkhaba khap), Yakkha (autonym yakkha, ?yakkh$a b a$ ), Limbu (autonym yakthuy, yakthupba), Dumi (autonym roPdi). In keeping with this convention I shall refer to Gvozdanović's data as Yakkha.

\begin{tabular}{|c|c|c|c|}
\hline & \multicolumn{3}{|c|}{ Abbreviations } \\
\hline 1 & first person & s & singular \\
\hline 2 & second person & d & dual \\
\hline 3 & third person & $\mathrm{p}$ & plural \\
\hline & & ns & non-singular \\
\hline A & agent of a transitive verb & & \\
\hline $\mathrm{P}$ & patient of a transitive verb & PT & preterite \\
\hline S & subject of an intransitive verb & NPT & non-preterite \\
\hline $\mathrm{nf}$ & prefixal slot & $\rightarrow$ & indicates the direction of \\
\hline & suffixal slot & & a transtive relationship \\
\hline$\Sigma$ & verb stem & NEG & negative \\
\hline
\end{tabular}

2. The Omruwa Yakkha verb data

Gvozdanović provides the affirmative simplex paradigm of the transitive verb mokma 'to beat', with the stems -mok- and, before $/ \mathrm{m} /$, -mong-. The data 


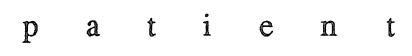

$1 \mathrm{~s}$

1 di

1 de

1 pi

1pe

$2 s$

$2 d$

$2 p$

$3 s$

$3 d$

$3 p$

1di

1de

g

$1 \mathrm{pi}$

1pe

e

n

$2 p$

t
.

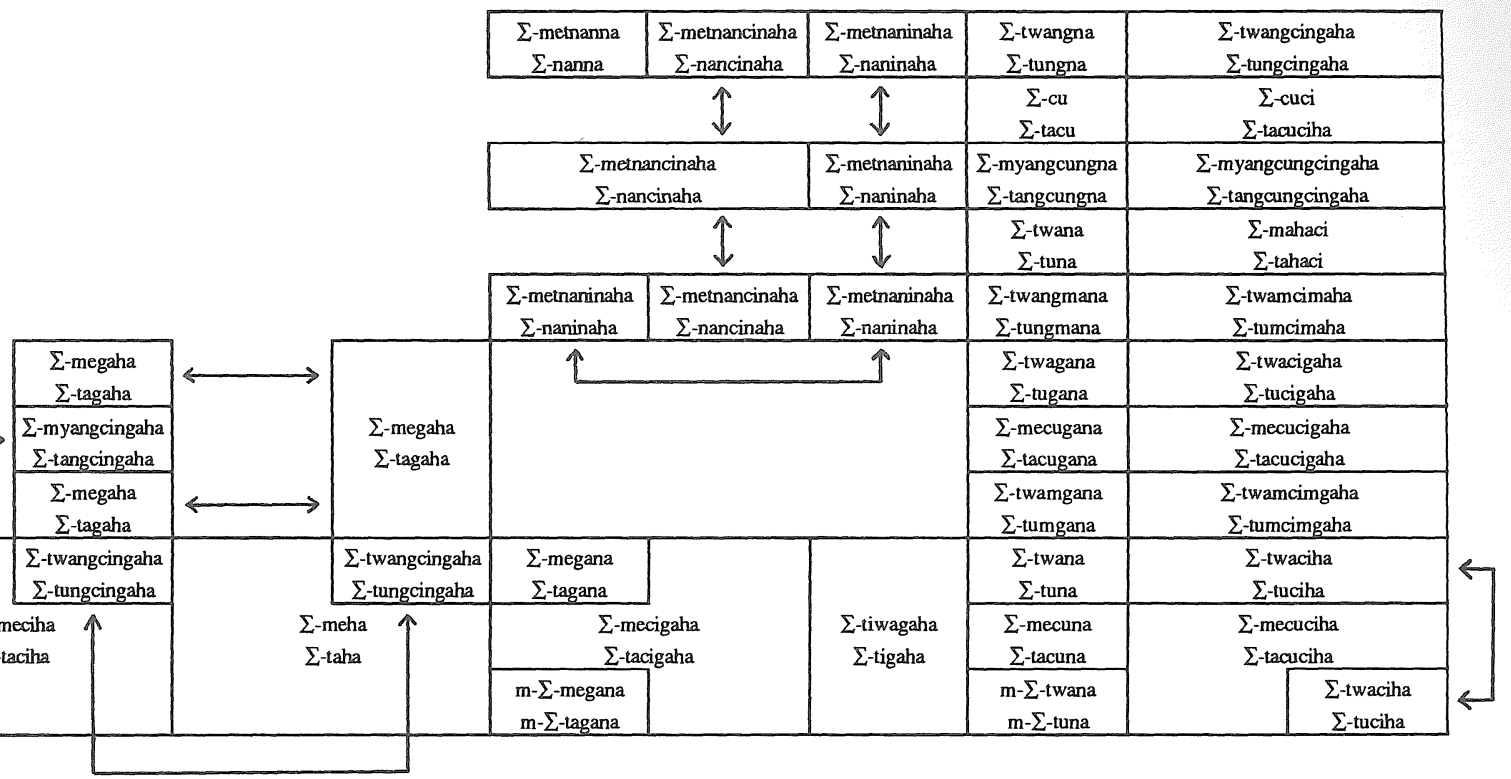


recorded by Gvozdanovic have been rearranged in an orderly fashion in the diagram above showing the affixes of the transitive paradigm, whereby the symbol $\Sigma$ represents the verb stem. The arrows connect forms which are formally identical and reflect the syncretism Gvozdanovic observed in the conjugation.

A comparison of this conjugation with the more complete Lohorung and Yamphu paradigms leaves the impression that the syncretism in the Yakkha paradigm is due to decay of a more complete conjugation. This decay may be idiolectal in view of the fact that the single informant spent the second half of his life outside of Yakkha speaking homeland. On the other hand, syncretism is a characteristic trait of verbal agreement systems in decay perhaps best illustrated by comparing the elaborate Bahing verbal paradigm recorded by Hodgson in the early nineteenth century with the simplified modern Bahing conjugation (van Driem, 1991a). In view of the possibility of a defective idiolect, which the data evoke to my mind, and because of the impossibility of assessing the data without entertaining speculations of my own concerning the observed patterns, I have provided a possible interpretation in the present article for Gvozdanovićs data.

The forms $<$ mya met $\sim m e>$ are found haphazardly in non-preterite forms throughout the paradigm, viz. in $2 / 3 \rightarrow 1$ s and $1 \mathrm{de} \rightarrow 3$ forms as $<-m y a>$, in $1 \rightarrow 2$ forms as $<-$ met $>$, and in $2 / 3 \rightarrow 1 \mathrm{~ns}, 3 \rightarrow 2 \mathrm{~s} / 2 \mathrm{~d}, 3 \mathrm{~d} \rightarrow 3 \mathrm{~s}, 3 \mathrm{~d} \rightarrow 3 \mathrm{~ns}$ and $3 \mathrm{p} \rightarrow 3 \mathrm{~d}$ forms as $<-m e>$. I venture to speculate that these forms might be what I call an aspectivizer in the Kiranti context, i.e. an auxiliary in the form of an accretion to the main verb stem which adds an Aktionsart to the meaning of the main verb. Perhaps we are dealing with an aspectivizer akin in meaning to Nepali hălnu, expressing assurance on the part of the speaker about the definite performance of the designated action or the validity of its result. The author's experience is that the elicitation of verbal paradigms usually yields many aspectivized forms and even 'incorrect' responses if a paradigm is elicited from an informant in one session, which - with an entire paradigm of the elaborate Kiranti type - is certainly a tedious task for an informant. On the basis of comparative evidence, e.g. Limbu -mukt-/-muk- 'strike, sound (of a bell, clock, musical instrument)', I should like to speculate that the Yakkha verb has an ante-vocalic stem -mokt- and an ante-consonantal stem -mok(-mong- before $/ \mathrm{m} /$ ). If this assumption is true, then cases of preterite/nonpreterite homophony might arise due to homophony of stem final $/ \mathrm{t} /$ with the preterite suffix $<-t>$. In such instances an informant willing to please the linguist might employ an aspectivizer in order to explicitly differentiate nonpreterite from preterite forms. In fact, the post-syllabic final $/ \mathrm{t} /$ of the stem is visible before a vowel in all non-preterite forms in Gvozdanović's material where this aspectivizer is lacking, viz. in $1 \mathrm{~s} \rightarrow 3,1 \mathrm{pi} \rightarrow 3 \mathrm{~s}, 1 \mathrm{pe} \rightarrow 3,2 \mathrm{~s} \rightarrow 3,2 \mathrm{p} \rightarrow 3$, $3 s \rightarrow 3,3 p \rightarrow 3 s, 3 p \rightarrow 3 p$ and $3 \rightarrow 2 p$ forms.

If the affix $<$ mya met $>$ is not synchronically or historically an aspectivizer in the Yakkha paradigm, we are dealing in the comparative context with an anomalous affix with an unknown meaning. When the recorded Yakkha forms have been shorn of this aspectivizer, an analysis of the remaining agreement morphemes yields the following possible analysis.

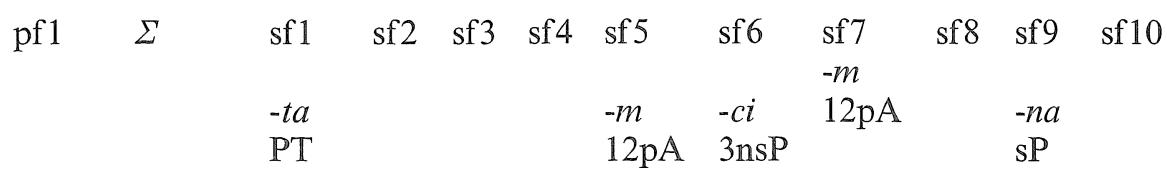




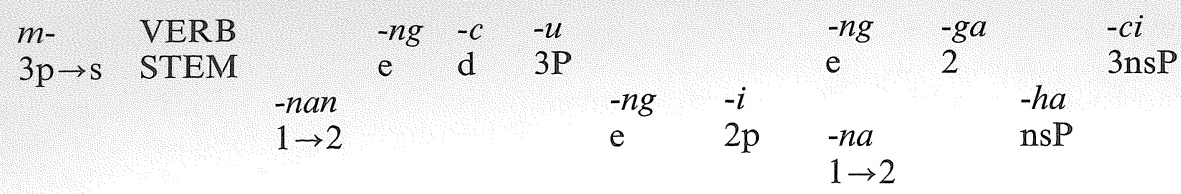

The prefix $<m->$ marks the transitive relationship between a third person plural agent and a singular patient and occurs in the $3 p \rightarrow 1 s, 3 p \rightarrow 2 s$ and $3 p \rightarrow 3 s$ forms.

The suffix $<-t a\rangle$ marks preterite tense and has a regular ante-vocalic allomorph $\langle-t\rangle$ before the third person patient suffix $\langle-u\rangle$ and the second plural suffix $<-i\rangle$. The preterite suffix does not occur in $1 \rightarrow 2$ forms which, if my hypothesis concerning the presence of aspectivizers in the elicited forms is correct, exhibit preterite/non-preterite homophony. The $1 \rightarrow 2$ portemanteau $<-n a n>$ marks the transitive relationship between a first person agent and a second person patient. This morpheme occurs as a copy morph $<-n a>$ in the copy position, suffixal slot 7 , following the first and second person dual morpheme $<-c i\rangle$ or the second person plural morpheme $<-i>$. The fact that preterite suffix and $1 \rightarrow 2$ portemanteau $<-$ nan $>$ do not co-occur is an argument to support ascribing $<-$ nan $>$ to the same slot in the affixal string of the verb.

The suffix $\langle-n g\rangle$ is an exclusive morpheme, i.e. marks exclusive of addressee. It occurs in all forms specific for first singular, first dual exclusive or first plural exclusive actant except for 1 pe $\rightarrow 3$ ns forms. The exclusive morpheme does not occur in $1 \rightarrow 2$ forms where exclusivity of agent is an implication of the $1 \rightarrow 2$ portemanteau $<-n a n>$. The exclusive morpheme occurs as a copy morph $<-n g a>$ in suffixal slot 7 after the second plural morpheme $<-i>$ and third person patient non-singular morpheme $<-c i>$. It also occurs as a second copy morph $<-n g>$ in suffixal slot 5 following the third patient morpheme $<-u>$.

The dual morpheme $<-c i>$ marks dual actant number. This morpheme has a regular allomorph $\langle-c\rangle$ before the third person patient morpheme $\langle-u\rangle$ in $\mathrm{d} \rightarrow 3$ forms in which it marks dual agent number. The morpheme marks duality of first or second person patient. Its occurrence in $3 p \rightarrow 3 d$ is unexplained, and the pattern of syncretism in the elicited non-singular $3 \rightarrow 3$ forms is odd.

The suffix $<-u>$ marks third person patient. It has a regular allomorph $<-w a\rangle$ in the non-preterite except following the dual morpheme $\langle-c i \sim-c\rangle$. It does not occur in the $1 \mathrm{pi} \rightarrow 3 \mathrm{~ns}$ forms, which appear to bear no systematic formal relationship to the corresponding $1 \mathrm{pi} \rightarrow 3 \mathrm{~s}$ forms, and the apparent occurrence of the suffix $\langle-u \sim-w a\rangle$ in $3 \mathrm{~s} \rightarrow 1 \mathrm{de} / 1$ pe forms is unexplained.

The suffix $<-m>$ marks plural number of a first exclusive or second person agent. The suffix occurs as a copy morph $<-m>$ in suffixal slot 7 following the non-singular number morpheme of a third person patient $<c i>$. This copy morph $<-m>$ has an allomorph $<-m a>$ before the non-singular patient morpheme $<-h a>$.

The suffix $<-c i>$ in suffixal slot 6 marks non-singular number of a third person patient. In the anomalous $1 \mathrm{pi} \rightarrow 3 \mathrm{~ns}$ forms the suffix occurs in a lone slot following the non-singular patient morpheme $<-h a>$. The suffix $<-i>$ in suffixal slot 6 marks plural number of a second person actant in forms specific for second plural actant except where second person number is indicated by the plural marker $\langle-m\rangle$. The suffix $\langle-i\rangle$ has a non-preterite allomorph $<-i w a>$ in $3 \rightarrow 2 p$ forms.

The suffix $<-g a>$ marks involvement of the second person in all forms 
with a second person actant except where second person is indicated by the $1 \rightarrow 2$ portemanteau morpheme. Following $\langle-g a\rangle$ in the suffixal string is a position occupied by the patient number morphemes $<-h a>$ and $<-n a>$. The suffix $<-n a>$ marks singular patient in all forms in which singular number of the patient actant except in $1 \mathrm{di} \rightarrow 3 \mathrm{~s}$ forms. The suffix $<-h a>$ marks non-singular patient number except in non-preterite $1 \mathrm{di} \rightarrow 3 \mathrm{~ns}$ forms. The suffix $<-h a>$ also occurs in $1 \mathrm{~ns} \rightarrow 2$ forms and $2 \mathrm{~d} \rightarrow 1 \mathrm{~s} / 1 \mathrm{de}$ forms where singular patient number is not distinguished. The resultant patterns of syncretism appear rather improbable: the $1 \mathrm{~s} \rightarrow 2 \mathrm{~d}, 1 \mathrm{de} \rightarrow 2 \mathrm{~s} / 2 \mathrm{~d}$ and $1 \mathrm{pe} \rightarrow 2 \mathrm{~d}$ forms are homophonous. The $1 \rightarrow 2 p$ and $1 \mathrm{pe} \rightarrow 2 \mathrm{~s}$ forms are homophonous. The $2 \mathrm{~d} \rightarrow 1 \mathrm{~s}$ and $2 \mathrm{~d} \rightarrow 1 \mathrm{de}$ forms are homophonous.

\section{Synchrony and diachrony}

Gvozdanović's explanations of Yakkha morphemes, each accompanied by an obfuscatory diagram, are-in a few cases-correct, if not lucid, e.g. her description of the $1 \rightarrow 2$ morpheme $<-$ nan $>$, and aspectivized <-metnan $>$ (Gvozdanović's 'nonpast'). Her description of the morpheme $<-$ mya $>$, which I presume to be an aspectivizer, is more typical: 'either the first set includes the single nonhearer not outside of the speech situation (i.e. the speaker) and the participants outside of the speech situation belong to two sets, or the second set equals the single nonhearer not outside of the speech situation (i.e. the speaker), irrespective of the first set'. In Gvozdanović's terminology the 'first set' is the agent, and the 'second set' is the patient of a transitive verb. The article reflects a spellbound response to the actant coding of the Kiranti verb, as if Gvozdanović were reliving the insights into person categories of the ancient Sanskrit and Greek grammarians. ${ }^{3}$ I have commented elsewhere on the currently fashionable tendency of rediscovering the person category (van Driem, 1992: 46).

Nonetheless Grozdanovic should be lauded for making available the first substantive new data on a little known language in 80 years. What bearing the poorly analysed data have on her expatiations on general linguistic phenomena, however, remains obscure. It would have been highly beneficial to TibetoBurman linguistics if Gvozdanovic were to have had the occasion to gather more data and gain a proper understanding of the conjugational systems which these data reflect. As it is, we have ample reason to be indebted to her for her unique contribution. Comparative hypotheses advanced on the basis of the Yakkha material should be viewed with caution, however, because of the quality of the data and the necessarily speculative nature of their interpretation.

In a series of studies (chronologically: van Driem, 1990a, 1992, 1991a, forthcoming $a$ ) in which the morphemically analysed conjugations of seven Kiranti languages were compared, the author developed a model of the ProtoKiranti verb representing a system of correspondences of the verbal agreement systems studied. The Yakkha verb for the most part turns out to fit snugly into the mould of the Proto-Kiranti conjugation with the exception of affixes at the tail end of the Omruwa suffixal string, viz. sf 8 to sf 10 , which are highly anomalous.

The only prefix in the Yakkha verb, the $3 p \rightarrow$ s portemanteau $<m->$, is

\footnotetext{
${ }^{3}$ Person was known as a linguistic category to the Sanskrit grammarians before Pānini (fifth century B.C.) and was independently recognized by the Greeks before Apollonius Dyscolos (second century A.D.). Western terminology is a continuation of the Greek tradition, viz. $\pi \rho o ́ \sigma \omega \pi \circ \nu \pi \rho \hat{\omega} \tau o \nu$

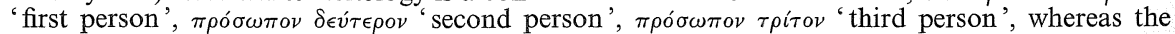
Sanskrit grammarians employed a different, if equally egocentric, terminology, viz. prathamapurusah 'first person', i.e. third person, madhyamapurusah 'middle person', i.e. second person, and uttamapurusah 'supreme person', i.e. first person.
} 
cognate with the only widely attested prefix in Kiranti, the third person plural agent morpheme *<me- $>$.

All Yakkha reflexes of Proto-Kiranti morphemes following the stem and hypothetical tensed auxiliary, $\mathrm{AUX}_{1}$, and preceding the hypothetical second auxiliary verb, $\mathrm{AUX}_{2}$, are unproblematic and reflect the same linear element order of the proto-morphemes in the model. The Yakkha preterite tense suffix $<-t a\rangle$ immediately after the verb corresponds to the Proto-Kiranti preterite morpheme $*<t \varepsilon>$. The Yakkha $1 \rightarrow 2$ portemanteau $<-$ nan $>$ is cognate with the Proto-Kiranti $1 \rightarrow 2$ portemanteau $*<$-nya $>$. The Yakkha exclusive suffix $<-n g>$ appears to represent a reanalysis - through expansion of the shared semantic component 'exclusive of person or persons addressed' - of the ProtoKiranti first person singular morphemes, 1s/NPT *<-na $>$ and $1 \mathrm{~s} / \mathrm{PT}$ $*<-$ an $>$, with which it corresponds both formally and in terms of relative position in the suffixal string. The Yakkha dual suffix $<-c\rangle$ corresponds to the two Proto-Kiranti morphemes, $12 \mathrm{dPS} *<-\mathrm{ci}>$ and $\mathrm{dAS} *<-$ ci $>$, probably the same morpheme in Proto-Kiranti but distinguished in the model because of the separate lives their respective reflexes went on to lead in the daughter languages. The Yakkha third person patient suffix $\langle-u\rangle$ is cognate with the Proto-Kiranti third person patient marker $*<-u>$.

Yakkha verbal agreement morphemes posterior to the position of the hypothetical second Proto-Kiranti auxiliary verb, $\mathrm{AUX}_{2}$, also for the most part correspond in a straightforward way to the proto-morphemes of the Kiranti conjugation. First, we shall turn to the Yakkha suffixes which tidily reflect the morphemes of the Proto-Kiranti model formally, semantically and in terms of their relative position in the suffixal string. The Yakkha first or second person plural agent morpheme $\langle-m\rangle$ is cognate to the Proto-Kiranti marker $*<-m>$ with the same meaning, form and position. The Yakkha third non-singular patient suffix $<-c i>$ is cognate to the Proto-Kiranti third person dual patient morpheme ${ }^{*}<-\mathrm{m}>$. The Yakkha second person plural ending $<-$ $i>$ appears to be cognate with the Proto-Kiranti inclusive marker $*<-i>$, which was reanalysed in Limbu as a first or second person plural patient/suffix morpheme, in Dumi as inclusive suffix, in Lohorung as a first person plural patient/subject marker, whereas the Bahing and Thulung reflexes express a first person plural inclusive actant. The meanings along which the reflexes of Proto-Kiranti inclusive $*<-i>$ developed in the daughter languages appear to have been 'inclusive' and, by implication, 'plural', which also correlates with the meaning of the modern Yakkha reflex.

In the Yakkha verb, the seventh suffixal slot is occupied by a number of copy morphemes: the $12 \mathrm{pA}$ copy $\langle-m\rangle$, exclusive $<-n g\rangle$ and the $1 \rightarrow 2$ portemanteau copy $<-n a>$. All Yakkha suffixes posterior to the copy morpheme position in the suffixal string are highly anomalous in the comparative context.

The Yakkha second person suffix $<-g a>$ corresponds formally and in terms of relative position with the Proto-Kiranti first person plural marker $*<-\mathrm{k}>$, with which it most certainly cannot be cognate. The latter was reanalysed as an exclusive marker in Limbu, Kulung, Thulung, Lohorung and Bahing. In view of this morpheme's tendency to develop along the lines of the meaning 'exclusive of person or persons addressed', if indeed this is not its original Proto-Kiranti meaning, a reanalysis of the morpheme to yield a modern second person marker seems highly improbable. Formally and semantically the Yakkha second person suffix $\langle-g a\rangle$ corresponds to the Limbu second person prefix $\langle k \varepsilon->$, although its position in the Yakkha finite would in that case be anomalous. Although it has been argued that prefixing is an 
older process in the Tibeto-Burman verb (DeLancey, 1989; Ebert, 1991), the cognacy of the Limbu and Yakkha second person markers, both situated peripherally at opposite ends of the finite verb, could suggest that at least the Kiranti second person marker $*<k \varepsilon>$ is a recent accretion (cf. van Driem, 1993a). Grierson (1909: 308) records the form 'moktugā' for '[thou] beatest', which corresponds to the Gvozdanović's preterite $2 \mathrm{~s} \rightarrow 3 \mathrm{~s}$ form moktugana, except for the last suffix, to which we shall now turn.

If the suffix $\langle-g a\rangle$ can be demonstrated to be a recent accretion in Yakkha, then this would hold a fortiori for the suffixes posterior to Yakkha $<-g a>$. The Yakkha singular patient suffix $<-n a>$ and non-singular patient suffix $<-h a>$ are without parallel in other attested Kiranti verbal agreement systems and would appear to be superfluous in the Yakkha paradigm itself, since they result in an overspecification of patient number in all finite forms. Grierson (1909: 308) already describes the Yakkha suffix 'nā' as a copula often added to the verb, which would mean that it is not a conjugational suffix at all, but an auxiliary in periphrastic constructions. The non-singular patient morpheme $\langle-h a\rangle$ in Gvozdanović's forms appears to be a cognate of the Limbu suffix -ha?, which serves as the plural marker in nouns but does not occur in Limbu verbs. Grierson (1909: 308) describes this Yakkha suffix, ' $h \bar{a}$ ', as a participial suffix, comparable to the plural suffix found in Yakkha adjectives. The occurrence of the Omruwa Yakkha third person non-singular patient suffix $<-c i>$ in sf 10 rather than sf6, i.e. in a position posterior to the Omruwa morphemes over-specifying patient number, is limited to the anomalous Omruwa $1 \mathrm{pi} \rightarrow 3 \mathrm{~ns}$ forms.

\section{Summary}

In conclusion, Gvozdanović's 'Yakkhaba' data are actually Yakkha data, which may imply that the Yakkha too call themselves or their language 'Yakkhaba'. The Yakkha data prompt Gvozdanović to embark on speculations of a general linguistic nature which have no clear bearing on the data she presents. An alternative analysis of her data has been proposed here. The Yakkha verbal agreement system is very much of the canonical Kiranti type and snugly fits the model of the Proto-Kiranti verb. The only anomalous characteristics are the posterior patient number suffixes, $\langle-n a\rangle$ and $\langle-h a\rangle$, which may not be conjugational affixes, and the second person suffix $\langle-g a\rangle$, which may be a recent accretion. The anomalous relative position in the affixal string of the latter suffix with respect to that of its Limbu cognate, the second person prefix $<k \varepsilon->$, might indicate that both affixes are not of great antiquity.

Gratitude is due to Gvozdanović for collecting and publishing the first new Yakkha data in 80 years. Yakkha is a language immediately threatened with extinction in its own homeland, and it is to be hoped that a capable linguist will devote himself or herself to the grammatical study of this language in the very near future so as to preserve more, and more reliable, data for posterity.

\section{BIBLIOGRAPHY}

Abhyankar, Kashinath Vasudev. 1961. A dictionary of Sanskrit grammar. Baroda: Oriental Institute.

Apollonius Dyscolos. 1878. Apollonii Scripta Minora a Richardo Schneidero edita continens (Grammatici Graeci recogniti et apparatu critico instructi, Partis II; Apollonii Dyscoli quae supersunt recensuerunt apparatum criticum commentarium indices adiecerunt Richardus Schneidero et Gustavus Uhlig, Vol. I), Leipzig: B. G. Teubner.

DeLancey, Scott. 1989. 'Verb agreement in Proto-Tibeto-Burman', BSOAS, LII, 2: 315-33.

Driem, George van. 1987. A grammar of Limbu, Berlin: Mouton de Gruyter.

Driem, George van. 1990a. 'An exploration of Proto-Kiranti verbal morphology', Acta Linguistica Hafniensia, 22: 27-48. 
Driem, George van. 1990b. 'The fall and rise of the phoneme $/ r /$ in Eastern Kiranti: sound change in Tibeto-Burman', BSOAS, LIII, 1: 83-86.

Driem, George van. 1991a. 'Bahing and the Proto-Kiranti verb', BSOAS, LIV, 2: 336-56.

Driem, George van. 1991b. 'Taal en identiteit: Indo-Arisch expansionisme in oostelijk Nepal', Bijdragen tot de Taal-, Land-en Volkenkunde, 147/1: 61-73.

Driem, George van. 1992. 'Le proto-kiranti revisité, morphologie verbale du lohorung', Acta Linguistica Hafniensia, 24: 33-75.

Driem, George van. 1993a. 'The Proto-Tibeto-Burman verbal agreement system', BSOAS, LVI, 2: 292-334.

Driem, George van. 1993b. A grammar of Dumi. Berlin: Mouton de Gruyter.

Driem, George van. forthcoming $a$. 'A new analysis of the Limbu verb'.

Driem, George van. forthcoming $b$. A Grammar of Lohorung.

Ebert, Karen. 1991. 'Inverse and pseudoinverse prefixes in Kiranti languages: evidence from Belhare, Athpare and Dungmali', Linguistics of the Tibeto-Burman Area, 14/1: 73-92.

Grierson, George A. 1909. Linguistic Survey of India. Vol. III: Tibeto-Burman family, Part I, General introduction, specimens of the Tibetan dialects, the Himalayan dialects and the North Assam group. Calcutta: Superintendent of Government Printing, India.

Gvozdanović, Jadranka. 1989. 'How synchrony of a language reveals its diachrony (principles of analysis and classification)', Folia Linguistica Historica, Acta Societatis Linguistica Europex, VII (1-2), 421-445.

Hodgson, Brian Houghton. 1826. 'Comparative vocabulary of the languages of the broken tribes of Népál', Journal of the Asiatic Society of Bengal, XXVI (no. v), 317-522.

Rutgers, Roland. 1992a. 'De naald en de koeievlaai, een verkenning van Yamphu morfologie aan de hand van een tekst', Rijksuniversiteit te Leiden: unpublished Master's thesis (kleine doctoraalscriptie).

Rutgers, Roland. 1992b. 'Een morfeemanalyse van het Yamphu simplex-werkwoord', Rijksuniversiteit te Leiden: unpublished Master's thesis (grote doctoraalscriptie).

Sluiter, Ineke. 1990. Ancient grammar in context: contributions to the study of ancient linguistic thought. Amsterdam: Uitgeverij van de Vrije Universiteit.

Staal, Frits (ed.). 1972. A reader on the Sanskrit grammarians. Cambridge, Mass.: Massachusetts Institute of Technology Press.

Weidert, Alfons and Bikram Subba (=Dillī Vikram Iñvābā). 1985. Concise Limbu grammar and dictionary. Amsterdam: Lobster Publications. 